\title{
LA ACCIÓN DE SUBROGACIÓN EN EL CONTRATO DE SEGURO MARÍTIMO, DESDE LA JURISPRUDENCIA $\Upsilon$ EL DERECHO COMPARADO
}

A AÇÃO SUB-ROGATÓRIA NO CONTRATO DE SEGURO MARÍTIMO, A PARTIR DA JURISPRUDÊNCIA E DO DIREITO COMPARADO

\section{THE SUBROGATION ACTION IN THE MARINE INSURANCE CONTRACT, FROM JURISPRUDENCE AND COMPARATIVE LAW}

\section{Renato Pezoa Huerta ${ }^{1}$}

Licença CC BY:

Artigo distribuído sob os termos Creative

Commons, permite uso e distribuição

irrestrita em qualquer meio desde que o autor credite a fonte original.

\begin{abstract}
Resumen: El presente artículo estudia en general, la institución jurídica de la subrogación y su asunción como principio fundamental del contrato de seguro, analizado bajo un enfoque dicotómico de "principio-acción", esto es, por un lado, como un elemento fisonómico del contrato de seguro marítimo, y por el otro, como una acción judicial de las Compañías de Seguros, tomando en consideración los requisitos para su procedencia y sus efectos. Luego se enfoca en el seguro marítimo, analizando casos de jurisprudencia, y la legislación de Derecho Marítimo Comparado
\end{abstract}

Palabras clave: Subrogación como acción; subrogación como principio informativo del seguro; indemnización; seguro marítimo.

Resumo: Este artigo estuda em geral, a instituição legal da sub-rogação e sua assunção como princípio fundamental do contrato de seguro, analisado sob uma abordagem dicotômica de "princípioação", ou seja, por um lado como elemento fisionômico do contrato de seguro marítimo, e por outro lado, como uma ação judicial das Companhias de Seguros, levando em consideração os requisitos para seu processo e seus efeitos. Em seguida, concentra-se no seguro marítimo, analisando casos de jurisprudência, e a legislação do Direito Marítimo Comparado.

Palavras-chave: Sub-rogação como uma ação; sub-rogação como um princípio informativo de seguro; indenização; seguro marítimo.

1 Universidad Bolivariana de Santiago de Chile (LL.B.). Máster en Dirección y Desarrollo Directivo (MBA) Especializado en Derecho Internacional por la Universidad Antonio de Nebrija, Madrid, en programa conjunto con CEREM IBS, España. "Numéraire" de la Association Henri Capitant des amis de la culture juridique française, París, France. Chile. E-mail: renato@pezoapizarro.cl. 
Abstract: This article studies, in general, the legal institution of subrogation and its assumption as a fundamental principle of the insurance contract, analysed using a dichotomous "principle-action" approach, i.e., on the one hand, it is seen as a physiognomic element of the marine insurance contract and on the other, as a judicial action of Insurance Companies, taking into consideration the requirements for its legitimacy and its effects. The focus of this work then shifts to maritime insurance, analysing cases of jurisprudence and the legislation of Comparative Maritime Law.

Keywords: Subrogation as an action; subrogation as an informative principle of insurance; indemnity; marine insurance.

\section{INTRODUCCIÓN}

La voz "subrogación", procede etimológicamente del latín subrogatio, cuya significancia es "sustituir, reemplazar, cambiar una persona o una cosa por otra". Jurídicamente, existen dos tipos de subrogación, una real y otra personal, interesando esta última, al seguro marítimo.

La subrogación consiste, consecuencialmente, en sustituir una persona por otra, en tales términos que la nueva pase a ocupar la misma situación jurídica que el sujeto primitivo.

En el ámbito de los seguros marítimos, y al igual que en todo contrato, existe una parte acreedora y otra deudora. Será deudor, el asegurado, y acreedor, el asegurador, cuando el primero deba pagar al segundo, la prima. En cambio, será deudor, el asegurador, y acreedor, el asegurado, cuando el primero deba al segundo, la indemnización total o parcialmente, una vez acaecido o verificado el siniestro marítimo.

Cuando el asegurador paga, total o parcialmente la indemnización al asegurado, por verificarse el siniestro marítimo cubierto por el seguro, emerge para la aseguradora, la posibilidad jurídica de accionar en contra del tercero responsable que causó el mentado siniestro, tal y como lo hubiere hecho el asegurado por sí y para sí, en el caso que no hubiese mediado el respectivo contrato de seguro.

El presente artículo propone analizar, describir y determinar el fundamento de la acción de subrogación en el contrato de seguro marítimo, desde su origen en el principio de subrogación, que da fisonomía y es axioma del seguro propiamente tal, y las fórmulas o hipótesis factuales que establece la prótasis normativa de Derecho Marítimo a su respecto, esto es, las condicionantes de procedencia que han construido diversas legislaciones, y cómo se ha reforzado, este instituto, a través de la jurisprudencia, estableciendo principalmente sus efectos.

\section{LA SUBROGACIÓN COMO PRINCIPIO DEL SEGURO MARÍTIMO.}

La subrogación es un principio que informa la estructura del contrato de seguro marítimo, y encuentra su fundamento en la indemnización que paga el asegurador al asegurado con ocasión del 
siniestro cubierto en la póliza. De este modo, la doctrina de la subrogación se deriva y refuerza bajo el principio de indemnización que, a su turno, es la obligación principal del asegurador.

La sección 79 de la "Marine Insurance Act" consagra el denominado derecho de subrogación, en los siguientes términos:

(1) Cuando el asegurador paga por una pérdida total, sea por el total, o en el caso de parte de los bienes de la materia asegurada, en virtud de ello se habilita para tomar el interés del asegurado en lo que quede de la materia asegurada por la que pagó, y de esta manera se subroga en todos los derechos y acciones del asegurado y respecto de tal materia asegurada, desde el momento del siniestro que causó tal pérdida. (2) Sujeto a las normas que continúan, cuando el asegurador paga por una pérdida parcial, no adquiere título en la materia asegurada, o tal parte de ella que quede, pero él es subrogado en todos los derechos y acciones del asegurado en y respecto de la materia asegurada desde la fecha del siniestro que causó la pérdida, en la medida en que el asegurado ha sido indemnizado, de acuerdo a esta ley, por tal pago de la pérdida.

La explicación de su existencia aflora en que, si no mediare la institución de la subrogación, y una vez que el asegurador paga la indemnización del daño al asegurado, este último podría ejercitar las correspondientes acciones de reparación en contra del tercero responsable del siniestro marítimo, convirtiendo el contrato de seguro en una fuente de ganancia o beneficios, toda vez que se vería favorecido con el pago de la indemnización del asegurador y, por la otra, con la indemnización que obtenga luego de accionar privadamente en contra del tercero responsable del siniestro. Esto es rechazado por legislaciones como la chilena, en su derogado artículo 517 del Código de Comercio, que disponía "(...) respecto del asegurado, el seguro es un contrato de indemnización, y jamás puede ser para él la ocasión de una ganancia". No obstante, la jurisprudencia en materia de seguros marítimos se pronunció en un sentido contrario, sin aborrecer del todo la instancia de doble enriquecimiento.

La Jurisprudencia del Derecho Inglés, resolvió que el derecho a una compensación o indemnización que obtiene el asegurado de parte del tercero causante del siniestro marítimo, no es un obstáculo para que pueda reclamar a la aseguradora en virtud de la póliza². En un sentido similar, se resolvió que el derecho del asegurado a reclamar contra un tercero, no se ve perjudicado por el derecho de indemnización en virtud de una póliza de seguro ${ }^{3}$. Con independencia de las precedentes citas jurisprudenciales del Derecho Marítimo inglés, la doctrina de los autores es conteste en señalar que la subrogación supone la herramienta más eficaz para prevenir el doble enriquecimiento de parte del asegurado ${ }^{4}$. Así también, con bastante énfasis, Brunetti ${ }^{5}$, ha señalado:

2 Casos emblemáticos en el Derecho Marítimo inglés, a su respecto, son Cullen vs Butler (1816); Dickenson vs Jardine (1868); y Collingridge vs Royal Exchange Assurance (1877)

3 En esta sede, son importantes los casos de Bradbourn vs Great western Railway (1874); Dickenson vs Jardine (1868); y en el Repertorio de Lloyd's de Londres, The Yasin (1979).

4 DERHAM, Sean. Subrogation in Insurance Law., Australia: Law Book Co.,1985, p. 86. GOFF, Robert; JONES, Gareth. The Law of Restitution. Sexta edición. Harvard Law Review Association, Cambridge, 1969, pp.12011206.

$5 \quad$ BRUNETTI, Antonio. Derecho Marítimo Privado Italiano. Bosch Editores, Barcelona, 1950, p. 767 
El asegurado, resarcido del daño en los límites de cuanto ha recibido, no tiene ya acción alguna contra el tercero responsable, sustituyéndole a él, el asegurador, porque si el objetivo del seguro es el de proteger al asegurado, ningún beneficio deben retirar de ello los terceros que son extraños y que deben responder de los propios hechos.

De lo expuesto, fluye prístino que la subrogación es un principio fundamental que evita el enriquecimiento del asegurado, a través del ejercicio de acciones en contra de su asegurador cocontratante en el seguro marítimo, y conjuntamente en contra del tercero responsable del siniestro. Es un principio ya asentado en la fisonomía del contrato de seguro, tal y como lo ha reseñado García $^{6}$, al decir

[la subrogación] constituye un principio de general aceptación en el universo marítimo de que el asegurador, por el hecho del pago del siniestro, se subroga al asegurado en los derechos y acciones que éste tenga contra terceros, responsables en razón del siniestro, a contar desde el momento en que ocurrió el siniestro causante del daño, pérdida, etc. (...) La subrogación entra a conferir al asegurador los derechos que aquel tenía en contra de terceros. Por ello debe ser interpretada en un sentido estricto.

En definitiva, la teoría de la subrogación en cuanto principio, emerge no solo de los axiomas de justicia y equidad como se ha citado precedentemente, sino que obedece en todo caso, y en mi opinión, a una máxima que propende a evitar la impunidad del tercero que con ocasión de su dolo o culpa, causó un daño al asegurado.

\section{LA SUBROGACIÓN COMO ACCIÓN DEL ASEGURADOR.}

La subrogación presenta una naturaleza dicotómica tanto como principio, y a su vez como acción. Es, en definitiva, el asegurador quien estará legitimado para adjetivar esta substancia del seguro. La afirmación precedente emerge desde que al asegurador le corresponden las prestaciones, de cualquier tipo, que pudiera percibir el asegurado de parte del tercero que ha causado el siniestro marítimo, fundamentalmente cuando el asegurado pudiere navegar en la consecución de obtener una indemnización adicional de parte de dicho tercero, ejercitando sus derechos y acciones en naturaleza. Para esto, el asegurador deberá oportunamente considerar, tempus facit aerumnas leves, si el asegurado ha percibido o no, alguna prestación previa al cumplimiento del pago de la indemnización a que se encuentra obligado dicho asegurador.

De este modo, si el asegurado ha percibido algún beneficio de parte del tercero que causa el siniestro marítimo, antes de la indemnización del asegurador, el efecto neto es reducir la responsabilidad de la aseguradora y el monto de la indemnización, a todo aquello que no cubrió lo

6 GARCÍA, Félix. Derecho del Transporte Marítimo. Comentarios, legislación comercial y administrativa. Ediciones Universitarias de Valparaíso. Valparaíso, 1993, p. 407 
dado o pagado por el tercero; enseguida, si el tercero paga al asegurado, ex post que el asegurador haya cumplido con su obligación indemnizatoria, todas las prestaciones a que tenía derecho percibir el asegurado, serán para el asegurador?

Con amplitud irrestricta, el juez británico Brett $\mathrm{Lj}$, en el emblemático caso de "Castellain vs Preston", señala que con ocasión del pago de la indemnización del seguro, el asegurado debe ser indemnizado en su totalidad, pero nunca debe ser más que sólo indemnizado, exponiendo:

El fundamento mismo (...) de todas las normas que se han aplicado al derecho de los seguros es éste, a saber, que el contrato de seguro contenido en una póliza marítima o de incendio es un contrato de indemnización, y sólo de indemnización, y que este contrato significa que el asegurado, en caso de una pérdida contra la que se ha hecho la póliza, será indemnizado en su totalidad, pero nunca será más que totalmente indemnizado. Este es el principio fundamental del seguro, y si alguna vez se presenta una propuesta que esté en desacuerdo con él, es decir, que impida que el asegurado obtenga una indemnización completa, o que dé al asegurado más que una indemnización completa, esa propuesta debe ser ciertamente errónea.

A modo germinal, la acción de subrogación del asegurador proviene de la completa satisfacción de las acreencias del asegurado, tomando en consideración que al momento de verificarse el siniestro marítimo, al asegurador le asiste la obligación de indemnizar el daño sufrido y, consecuentemente, al asegurado le toca percibir dicha indemnización como acreedor. De esta forma, acaecido el riesgo marítimo, y ocurrido el daño, la asunción de posiciones jurídicas es la de deudor para el asegurador, y acreedor para el asegurado. Frente a este modo de operar en la relación contractual, si el asegurado ya ha sido indemnizado por el asegurador, este último habrá satisfecho su acreencia. Por lo tanto, emergerá el derecho del asegurador de ocupar la posición jurídica de su antiguo acreedor. Así las cosas, el artículo 1609 del Código Civil Chileno, señala que "[s]e subroga un tercero en los derechos del acreedor, o en virtud de la ley, o en virtud de una convención del acreedor". A su turno, el artículo 534 del Código de Comercio de Chile dispone que "[p]or el pago de la indemnización, el asegurador se subroga en los derechos y acciones que el asegurado tenga en contra de terceros en razón del siniestro"8.

Es claro, entonces, que entre el asegurado y el tercero que causa el daño, emerge una obligación de indemnizar, en la que el primero es el acreedor y el segundo el deudor; ergo, mediando para el asegurado la existencia de un seguro marítimo que, claramente supone otra relación jurídica, esta vez con una Compañía de Seguros, será este último en cuanto asegurador, quien pasará a ocupar el sitial del asegurado al momento que le indemnice el daño que el tercero le ha causado, ejercitando los derechos que a ese asegurado le corresponderían en naturaleza. Por lo pronto, y siguiendo a

$7 \quad$ BENNETT, Howard. The Law of Marine Insurance. Second Edition. Oxford University Press. Oxford, 2005, p. 777

8 Dicha regla del artículo 534 del Código de Comercio de Chile, si bien se enmarca en la regulación del Contrato de Seguro en general, es igualmente aplicable al Seguro Marítimo por expreso mandato del artículo 1158 del mismo cuerpo legal, que señala "se aplicarán a los seguros de que trata este Título (seguros marítimos), salvo en las materias que regule de otra manera, las disposiciones de las secciones primera y segunda del Título VIII del Libro Il de este Código". 
Bennett ${ }^{9}$, "la doctrina de la subrogación permite al asegurador, acceder a los derechos del asegurado para responsabilizar a terceros por causar estos, el siniestro cubierto".

\section{REQUISITOS DE PROCEDENCIA DE LA ACCIÓN DE SUBROGACIÓN}

Para que el asegurador pueda ejercitar la acción de subrogación, debe cumplir, en principio, con su obligación. Es necesario prevenir que, en diversas legislaciones, como la chilena ${ }^{10}$, colombiana ${ }^{11}$, española ${ }^{12}$ e incluso francesa ${ }^{13}$, el requisito primigenio que debe acontecer es, fundamentalmente, el pago efectivo de la indemnización.

La jurisprudencia inglesa, preferentemente por lo resuelto en la Corte de Apelación Británica, ha fallado con un criterio sistémico, idéntico al de las legislaciones comparadas supra, siguiendo los razonamientos autorizados del Juez McCardie ${ }^{14}$, que

(...) el principio de subrogación es siempre un ingrediente latente e inherente al contrato de indemnización, pero (...) no se hace operativo o exigible hasta que el asegurador efectúe el pago. Se deriva su vida del contrato original. Adquiere su fuerza operativa a partir del pago de ese contrato (...) En mi opinión, la esencia del asunto, es que la subrogación surge no sólo del pago, sino del pago real de la indemnización, junto con el hecho de que se haya efectuado en virtud del contrato básico y original de seguro.

Pero la satisfacción de la acreencia del asegurado, esto es, la reparación o indemnización del daño, en concepto de la Corte de Apelación Británica, debe ser total, para que de este modo, opere de pleno derecho la acción subrogatoria del asegurador. Así, en el caso "Page vs Scottish Insurance Corp." El Juez Scrutton, falló de la siguiente manera:

Con respecto al asunto concreto, creo que el derecho a subrogarse en los derechos del asegurado, no pasa al asegurador hasta que haya satisfecho todas las reclamaciones en virtud de la póliza; de pronto, si se tiene un coche, un accidente, una póliza y una prima pagada, no creo que el asegurador pueda pretender subrogarse sino hasta que haya satisfecho todas las reclamaciones de esa póliza, y pagadas en virtud de esa única prima, con respecto a ese único accidente y a ese único coche.

$9 \quad$ BENNETT, Howard. The Law of Marine Insurance. Second Edition. Oxford University Press. Oxford, 2005, p. 778

10 El contenido del citado artículo 534 del Código de Comercio de Chile dispone que "[p]or el pago de la indemnización, el asegurador se subroga en los derechos y acciones que el asegurado tenga en contra de terceros en razón del siniestro".

11 El Código de Comercio de Colombia dispone "el asegurador que pague una indemnización".

12 La Ley española de seguros 50/1980 de 08 de octubre, dispone con claridad en su artículo 43 que "el asegurador, una vez pagada la indemnización, podrá ejercitar los derechos y las acciones que por razón del siniestro correspondieran al asegurado frente a las personas responsables del mismo, hasta el límite de la indemnización".

13 El artículo L-121-12 del Código de Seguros de Francia, indica que la acción sólo es admisible con posterioridad al pago efectivo. En efecto, el artículo hace referencia a "el asegurador que ha pagado una indemnización"

14 La pluma autorizada del Juez McCardie puede leerse en "John Edwards \& Co. Vs Motor Union Insurance Co. (1922); y otros razonamientos jurisprudenciales de Derecho Marítimo inglés, en "Dickenson vs Jardine" (1868); "Simpson \& Co. vs Thomson" (1877), y el ya citado caso de "Castellain vs Preston" (1883). Esta línea jurisprudencial emerge de la correcta interpretación de la Marine Insurance Act de 1906. 
En el orden procesal, y al momento de incoar la acción de subrogación, el asegurador deberá probar que efectivamente pagó la indemnización al asegurado. Así lo establece en el Derecho Comparado, por ejemplo, el Código Civil Chileno, en su artículo 1698, al disponer que "incumbe probar las obligaciones o su extinción al que alega aquéllas o ésta". Para este efecto, el Código de Comercio de ese país, señala su artículo 119, que "el deudor que paga tiene derecho a exigir un recibo (...) El recibo prueba la liberación de la deuda". Una regla semejante se reproduce en el Código de Procedimiento Civil de Colombia, que en su artículo 177 señala "incumbe a las partes probar el supuesto de hecho de las normas que consagran el efecto jurídico que ellas persiguen". Finalmente, la doctrina francesa ${ }^{15}$ señala

La prueba del pago corresponde al asegurador y se llevará a cabo según las modalidades previstas en el derecho común de la prueba. En el campo civil, ésta deberá probarse por escrito, en materia comercial son admisibles todos los medios probatorios. La constancia de subrogación constituye el modo normal de prueba.

Un último requisito de exigibilidad, es que el pago de la indemnización sea efectuado total o parcialmente por el asegurador. Así, el asegurador sólo tiene derecho a controlar la acción de subrogación con exclusividad, cuando ha indemnizado íntegramente al asegurado por todas las reclamaciones derivadas de la póliza en relación con el siniestro ${ }^{16}$, y si dicha indemnización satisface en su totalidad la reclamación del asegurado por los daños que le causó el tercero ${ }^{17}$. Por otro punto, cuando el asegurador ha indemnizado solo parcialmente al asegurado, este último conservará aún después de ese pago parcial, el derecho a controlar el litigio contra el tercero responsable del siniestro marítimo. No debe perderse de vista, a este último respecto, que con ocasión de la subrogación, el asegurador ejercitará los derechos que primitivamente le asistían al asegurado. Por esta razón, si la indemnización efectuada por el asegurador es parcial, no le serán transferidos en su totalidad los derechos del asegurado, quien podrá todavía ejercerlos en contra del tercero responsable, hasta la satisfacción total de la acreencia insoluta. De este modo, la acción de indemnización todavía prevalece en el asegurado.

Lo anteriormente expuesto tiene ciertas limitaciones. Así, cuando el asegurado ejerce sus derechos contra el tercero que provoca el siniestro marítimo, tiene una obligación sustentada en la equidad y la máxima buena fe para su co-contratante del seguro marítimo, de salvaguardar los beneficios que el asegurador podría obtener si ejercitare la acción de subrogación.

15 BIGOT, Jean; con la colaboración de BEAUCHARD, Jean; HEUZÉ, Vincent; KULLMANN, Jérôme; MAYAUX, Luc; NICOLAS, Véronique. Traité de Droit des assurances. Tome 3. Le contrat d'assurance. Librairie Générale de Droit et de Jurisprudence. París, 2003. p. 119

16 Esta construcción jurisprudencial proviene del caso "Central Insurance Co. Ltd. vs Seacalf Shipping Corp (The Aiolos)" del año 1983, en el Repertorio 25 de Lloyd's de Londres.

17 Algunos casos cruciales para esta construcción jurisprudencial, están en "Commercial Union Assurance Co. vs Lister" (1874); "Globe \& Rutgers Fire Insurance Co. vs Tuedell” (1927); y "Arthur Barnett Ltd. vs National Insurance Co. of New Zealand Ltd." (1965). 
Frente al caso en que el asegurador pague parcialmente la indemnización al asegurado, la jurisprudencia británica ha resuelto que, aun así, el asegurado debe demandar al tercero por la totalidad del siniestro, y no sólo por la parte del mismo, que quede pendiente tras el pago que hubiere efectuado el asegurador ${ }^{18}$.

Ahora bien, bajo la equidad y máxima buena fe con que debe actuar el asegurado, a fin de salvaguardar los intereses de la Compañía de Seguros, concernientes al ejercicio de la acción de subrogación, es indispensable que el asegurado ejercite las acciones contra el tercero responsable del siniestro, dentro de los plazos de prescripción. Para esto, la doctrina sugiere que en función del tiempo disponible, el asegurado se limite a invitar al asegurador a pagar el siniestro y, conjuntamente, a iniciar el procedimiento judicial que corresponda bajo la acción de subrogación; o podría también el asegurado, iniciar el litigio por sí mismo y luego invitar a la aseguradora a pagar la indemnización, a fin de que pueda luego, asumir el control del litigio ${ }^{19}$. Esta recomendación doctrinal no es antojadiza, y es de alguna forma, parte de la costumbre jurídica internacional, al momento de redactarse expresamente las pólizas marítimas modernas.

Lo anterior, se reafirma conforme lo señalado en todas las cláusulas de carga del "The Institute of London Underwriters", que imponen expresamente al asegurado, "el deber (...) de asegurarse de que todos los derechos contra los transportistas, comodatarios u otros terceros sean debidamente preservados y ejercidos." ${ }^{20}$ Idéntica regla se establece en las "International Hull Clauses" de 01 de noviembre del año 2003, específicamente en la cláusula 49.1 que, si es incorporada en un contrato de seguro marítimo, impone al asegurado las siguientes obligaciones, destinadas a fortalecer las perspectivas de recuperación respecto del tercero que causa el siniestro marítimo:

“El Asegurado deberá, independientemente de que el Asegurador le haya pagado [la indemnización por] una reclamación, o hayan acordado pagar una [indemnización por una] reclamación o una posible reclamación en virtud de este seguro, tomar medidas razonables para:

49.1.1. Evaluar tan pronto como sea posible si hay alguna posibilidad de recuperación respecto de terceros, con ocasión de los asuntos que dan lugar a una reclamación, o a una potencial reclamación bajo este seguro;

49.1.2. Proteger cualquier reclamación contra dichos terceros, si es necesario, mediante el inicio de procedimientos, y la adopción de medidas apropiadas para obtener la garantía de la reclamación de terceros;

18 Con esta claridad, se falló en el caso "Phoenix Assurance Co. vs Spooner" (1905).

19 LYNCH, Ben y BIRDS, John (Org.). MacGillivray on Insurance Law. 10ª edition. Sweet \& Maxwell, Londres, 2003 pp. 22-51.

20 Esto ocurre con las Cláusulas de Carga (A), (B), (C); y Cláusulas de Guerra (Carga); y Cláusulas de Huelga (Carga) 
49.1.3. Mantener a la(s) Aseguradora(s) Principal(es) y al Liquidador de Seguros designado (si lo hay), informados de las perspectivas de recuperación y de cualquier acción tomada contra terceros;

49.1.4. Cooperar con la(s) Aseguradora(s) Principal(es) en la realización de las gestiones que puedan ser razonablemente necesarias para el seguimiento de cualquier reclamación contra terceros".

Es relevante señalar que tanto las cláusulas de carga del "The Institute", como las "International Hull Clauses", no señalan consecuencias en caso que el asegurado incumpla con dichas obligaciones. Sí tendrán el efecto similar a una garantía, a cuyo respecto el asegurador podrá ejercitar acciones en contra del asegurado por daños y perjuicios ${ }^{21}$.

Un último requisito de procedencia de la acción de subrogación, viene dado por la responsabilidad del tercero. El artículo 2316 del Código Civil de Chile, dispone que "Es obligado a la indemnización el que hizo el daño (...)".

Cabe definir, quién es el tercero causante del daño, y qué tipo de responsabilidad es la que puede perseguirse a través de la acción de subrogación.

En este sentido, el tercero responsable puede ser tanto el Estado como un particular. Consecuentemente, la responsabilidad podrá ser extracontractual o contractual. Es imprescindible, a mayor abundamiento, que tanto el asegurado como el asegurador, prueben la efectiva responsabilidad del tercero y su obligación indemnizatoria.

\section{PRORRATEO DEL PRODUCTO DE LA ACCIÓN}

El prorrateo procede en caso que el asegurado no vea totalmente satisfecha la indemnización que le corresponde con ocasión del siniestro marítimo. De esto, se desprende que las prestaciones que pueda percibir el asegurado, provenientes de terceros, o por el incumplimiento imperfecto de la obligación del asegurador, resulten en una disminución del siniestro.

Es de general ocurrencia que el asegurado entable una acción contra terceros, cuando existe un déficit entre lo efectivamente indemnizado por el asegurador, versus el valor real del daño. Como se ha mencionado supra, al no quedar totalmente solucionada la acreencia del asegurado por un pago parcial de la indemnización del asegurador, dicha circunstancia dará derecho al asegurado para que pueda igualmente ejercer sus derechos en contra del tercero responsable, conforme las reglas generales en materia de indemnización de perjuicios. De este modo, si el asegurado ejerce la acción directamente contra el tercero responsable del siniestro, y el asegurador ha pagado parcialmente la indemnización, este último podrá beneficiarse del excedente que resulte de lo que ya ha solucionado, y la parte insoluta del daño.

21 Si bien no es una garantía propiamente tal, la jurisprudencia le ha dotado de esa naturaleza a través del caso "Alfred McAlpine plc vs BAl (Run-Off) Ltd." (2000) en el Repertorio de Lloyd's 352. 
Por otro punto, y en caso que una acción de subrogación se lleve a cabo con éxito, o que el asegurado reciba alguna prestación de parte del tercero responsable, con el objeto de propender a disminuir las pérdidas, se plantean ciertas dificultades.

En primer lugar, si el asegurado es totalmente compensado por la indemnización del seguro marítimo, es evidente que todas las sumas recuperadas por pagos efectuados por el tercero responsable, disminuyen la pérdida sufrida y, en consecuencia, el asegurador tendrá derecho a percibir ese dinero. Sin embargo, este derecho está limitado sólo al importe de lo efectivamente pagado al asegurado. Así ocurrió en el caso "Yorkshire Insurance Co. versus Nisbet Shipping Co. Ltd", donde un buque asegurado por $£ 72.000$, sufrió una pérdida real total, producto de un abordaje con una nave de la Armada canadiense, y donde este último fue responsable de dicha colisión. La Compañía de Seguros pagó $£ 72.000$ a título de indemnización, y los asegurados, con el consentimiento del asegurador, demandaron al Gobierno Canadiense por daños y perjuicios. Recuperaron el valor total del buque en su equivalente al momento de ocurrido el abordaje, que entonces valía, realmente, $£ 75.500$. Sin embargo, antes de que se pagara el dinero, la libra esterlina se devaluó, lo que culminó en que la suma pagada ascendiera, finalmente, a £125.000. El asegurado sólo devolvió al asegurador la cantidad de £72.000, y por esta razón, la Compañía de Seguros demanda al asegurado. En el juicio, el asegurador fracasa. Se resolvió en dicha instancia, que con independencia del pago efectuado por la parte aseguradora, la acción contra terceros sigue siendo, en derecho y no solo en forma, del asegurado, razón por la cual éste tiene derecho a sus frutos. La subrogación no es más que un mecanismo legal para evitar el enriquecimiento injusto que supondría permitir al asegurado, retener una indemnización en virtud de la póliza de seguro marítimo, y paralelamente, los frutos de un litigio contra el tercero responsable del siniestro, cuando en realidad, dicha percepción se reputaría como una doble recuperación. En este sentido, la subrogación debe contrastarse con la cesión de la acción al asegurador. La cesión transfiere el beneficio de la acción a la aseguradora, dándole derecho a retener la totalidad de la indemnización recuperada del tercero, incluyendo cualquier excedente sobre la indemnización pagada por la Compañía de Seguros al asegurado22.

En segundo lugar, si el asegurado no es totalmente indemnizado por el seguro marítimo, se plantea la cuestión de si tendrá derecho a la acción de indemnización por daños y perjuicios contra el tercero, que será necesaria para compensar el déficit del pago parcial de dicha indemnización. Como cuestión de principio general, mientras al asegurado no le hayan resarcido su pérdida en totalidad, no existe peligro de enriquecimiento injusto a través de una doble recuperación, que es aquello que la doctrina de la subrogación, pretende evitar. En la medida que la indemnización proveniente del seguro marítimo sea insuficiente para cubrir la totalidad de la pérdida sufrida, el asegurado tiene prioridad con respecto a los ingresos provenientes del tercero responsable. Este principio

22 Es decisivo para la comprensión de las diferencias existentes entre la acción de subrogación y la cesión de la acción al asegurador, la jurisprudencia de "Compañía Columbiana de Seguros versus Pacific Navigation Co." (1965), citada en BENNETT, Howard. The Law of Marine Insurance. Second Edition. Oxford University Press. Oxford, 2005, p. 795 
lógico de prioridad del asegurado, ha sido una construcción jurisprudencial firme y constante en el tiempo. Así, en el caso "Re Driscoll"23 el asegurado era un inquilino de un local dañado por un incendio. Como la indemnización de la aseguradora era insuficiente para que el asegurado pudiera cumplir con sus obligaciones de reparación, demandó a un subarrendatario por incumplimiento de las obligaciones de reparación de este último. El asegurador reclamó el derecho a los ingresos de esa acción intentada por el asegurado contra el subarrendatario, con preferencia a la indemnización completa del asegurado; reclamación que fue rechazada de plano por el Tribunal Superior de Irlanda, fallando en los siguientes términos:

"[La reclamación de la Compañía de Seguros] se basa en el derecho de subrogación, y el argumento de la compañía es que cualquier suma que recupere el asegurado, debe beneficiar a la compañía en razón de la cantidad que ya ha pagado al asegurado con ocasión del seguro, independientemente de si el asegurado ha sido totalmente indemnizado por la pérdida sufrida. A esto se opone el argumento del asegurado de que, hasta que no sea totalmente indemnizado, no está obligado a aportar nada a la Compañía. No tengo ninguna duda de que esta última opinión es la correcta. Un contrato de seguro contra incendios es sólo un contrato de indemnización, y creo que el fundamento de la doctrina de la subrogación, se encuentra en el principio de que nadie debe ser pagado dos veces en compensación por el mismo siniestro. El corolario de esto es que, un contrato de indemnización por pérdida, no debe tener el efecto de impedir que el asegurado sea pagado en su totalidad. No creo que esto se deba discutir".

En definitiva, se ha concluido que "sería manifiestamente injusto, negar al asegurado todos sus derechos y recursos con respecto al siniestro, cuando no se le ha indemnizado totalmente por el mismo"24 y que un asegurado "no debe enriquecerse injustamente por un pago excesivo, sino que tiene derecho a un pago completo antes de que el demandante de la subrogación reciba cualquier cosa". 25

\section{LOS EFECTOS DE LA SUBROGACIÓN}

Cuando el asegurado ha recibido totalmente el pago de la indemnización de parte del asegurador, perderá de inmediato sus derechos y acciones contra el tercero responsable, adquiriéndolas de pleno derecho, la aseguradora. Este es el denominado efecto translativo de la subrogación.

En este sentido, la Corte de Casación francesa resolvió que

aquel que, después de haber sido indemnizado, ha subrogado a su asegurador en sus derechos, pierde la calidad para accionar contra el responsable y no

23 Este caso se remonta al año 1918. No obstante, existen otros similares, donde es preciadísima la jurisprudencia de "Arthur Barnett Ltd. versus National Insurance Co. of New Zealand Ltd" (1965), "Ledingham versus Ontario Hospital Services Commision" (1979); y "Firestone versus Chubb Insurance Co. of Canada" (1995).

24 "Confederation Life Insurance Co v Causton" (1989) 60 DLR (4th) 372, 375 per Wallace JA (Court of Appeal of British Columbia), citado en BENNETT, Howard. The Law of Marine Insurance. Second Edition. Oxford University Press. Oxford, 2005, p. 796

25 "Bigl Estate v Alberta" (1989) 60 DLR (4th) 438, 441 per Laycraft CJA (Court of Appeal of Alberta), citado en BENNETT, Howard. The Law of Marine Insurance. Second Edition. Oxford University Press. Oxford, 2005, p. 796 
puede, salvo convención expresa o tácita que lo habilite, actuar en justicia en nombre de su asegurador ${ }^{26}$.

Conjuntamente con lo anterior, la subrogación legal está limitada al monto efectivamente pagado por el asegurador, en virtud del contrato de seguro marítimo. Así, si el perjuicio sufrido por el asegurado es superior al monto indemnizado por la Compañía de Seguros, este último sólo podrá recuperar la suma pagada.

\section{CONSIDERACIONES FINALES}

Las legislaciones de seguros marítimos de corte occidental, se construyen preferentemente en base a las fórmulas del Derecho Marítimo Inglés, y por el fenómeno condensativo de la costumbre internacional marítima, que ha dado paso al establecimiento de reglas, convenciones y tratados internacionales que han intentado regular la materia, principalmente por el carácter internacional de las relaciones jurídicas que emergen en la inmensidad del océano del Derecho Marítimo y de los Seguros.

Bajo este presupuesto, las legislaciones de seguros marítimos son generalmente referenciales, y cumplen un fin eminentemente regulador de las relaciones contractuales, sentando principios básicos de orientación para el desarrollo de estos acuerdos de voluntades, y propiciando una instancia de fortalecimiento a la parte "más débil" del contrato.

No obstante lo anterior, la principal "ley del seguro" es aquella que emerge de la autonomía privada de las partes, esto es, todo aquello que los contratantes, asegurado y asegurador, plasmen en la póliza del seguro, lo cual revestirá una modalidad de pacto vestido del contrato de seguro marítimo, y establecerá la imperatividad de las reglas que las partes han diseñado libre y espontáneamente. Este es el denominado principio o fenómeno de la lex privata. Considerando entonces, que el seguro y su vida jurídica dependen en gran medida de lo que las partes estipulen libremente, el perfeccionamiento, trascendencia y modernización de los institutos de seguros marítimos ha dependido fundamentalmente de dos fuentes: la jurisprudencia de los tribunales, y la integración legislativa.

Todas estas conclusiones son palmarias, evidentes o manifiestas, si se considera que las legislaciones de seguros, sólo se han ocupado de cimentar y reconocer los principios de la actividad aseguradora, más no han extendido su ámbito de regulación a los efectos que produce el ejercicio de tales principios o máximas. La subrogación es, indudablemente, un principio formativo del seguro marítimo, que propende a evitar el doble enriquecimiento del asegurado, sea que éste perciba la indemnización del asegurador $y$, además, la indemnización o prestaciones del tercero responsable del siniestro. El seguro jamás representará para el asegurado, una instancia de enriquecimiento, aunque la práctica cotidiana, muchas veces, demuestre todo lo contrario.

26 CASS. 1 re civ. 4 févr. 2003, №2003, №00-15.716, Resp, civ, et assur. 200, coom. №154, note GROUTEL H. 
Ergo, de ese principio, emerge la acción del asegurador, esto es, un derecho adjetivo cuyo objeto es recuperar todo lo que ha dado o pagado al asegurado, en razón de la indemnización del siniestro marítimo, ocupando su posición jurídica, y ejercitando sus acciones y derechos, como si realmente fuere el asegurado.

Conjuntamente con lo anterior, existen situaciones en que el asegurado no se desprende totalmente de sus derechos y acciones contra el tercero responsable del siniestro, y que podrá ejercitar privativamente, e incluso conjuntamente con el asegurador, todo con el objeto de satisfacer íntegramente sus acreencias que han emergido en razón del daño o siniestro marítimo del que ha sido víctima. Con claridad, entonces, la jurisprudencia ha fortalecido razonablemente los criterios de ejercicio de la acción de subrogación, y ha cumplido un verdadero rol de adalid de justicia para la determinación de sus efectos, todo con el fin último de dirimir adecuadamente los conflictos que nacen con ocasión del seguro marítimo.

El sentido social de la subrogación en cuanto principio, y su materialización jurídica a través de su adjetivación, busca evitar que el actuar doloso o culposo del tercero responsable del siniestro marítimo, quede en la absoluta impunidad. Este es un efecto social, sin perjuicio del carácter económico que evita el doble enriquecimiento del asegurado.

No obstante lo anterior, si la subrogación hace efectiva la responsabilidad del tercero que causa el siniestro marítimo, y por otro punto, evita el enriquecimiento injusto del asegurado, resulta realmente incomprensible el motivo por el cual el asegurador tendría que beneficiarse, como legitimado activo procesal, con el ejercicio de esta acción, habida consideración que la Compañía de Seguros ya estaría percibiendo una suma de dinero abultada por concepto de primas de parte del asegurado, por hacerse cargo de la transferencia de los riesgos marítimos de este último; y bajo el principio de atomización, ese riesgo marítimo se distribuye en todos los asegurados. ¿No es, entonces, un caso inverso de doble enriquecimiento, pero esta vez, a favor de las Compañías de Seguros?

\section{REFERENCIAS DE FUENTES CITADAS}

ANSIETA, Alfonso. Introducción al Seguro Marítimo. Ediciones Universitarias de Valparaíso. Valparaíso, 1976.

BARROILHET, Claudio. Derecho del Seguro Marítimo. Segunda Edición Actualizada. Librotecnia. Santiago de Chile, 2020 BENNETT, Howard. The Law of Marine Insurance. Second Edition. Oxford University Press. Oxford, 2005.

BIGOT, Jean; con la colaboración de BEAUCHARD, Jean; HEUZÉ, Vincent; KULLMANN, Jérôme; MAYAUX, Luc; NICOLAS, Véronique. Traité de Droit des assurances. Tome 3. Le contrat d'assurance. Librairie Générale de Droit et de Jurisprudence. París, 2003.

BRUNETTI, Antonio. Derecho Marítimo Privado Italiano. Bosch Editores, Barcelona, 1950

DERHAM, Sean. Subrogation in Insurance Law, Law Book Co., Australia, 1985

DUNT, John. Marine Cargo Insurance. Lloyd's Shipping Law Library. London, 2009. 
GARCÍA, Félix. Derecho del Transporte Marítimo. Comentarios, legislación comercial y administrativa. Ediciones Universitarias de Valparaíso. Valparaíso, 1993

GOFF, Robert; JONES, Gareth. The Law of Restitution. Sexta edición. Harvard Law Review Association, Cambridge, 1969 HUDSON, Geoffrey; MADGE, Tim, STURGES, Keith. Marine Insurance Clauses. Fifth Edition. Informa Law from Routledge. Oxfordshire, 2021.

JARAMILLO, Patricia. La subrogación en seguros. Depalma-Ibáñez. Pontificia Universidad Javeriana. Bogotá, 2013.

LYNCH, Ben; BIRDS, John (Org.). MacGillivray on Insurance Law. 10ª edition. Sweet \& Maxwell, Londres, 2003

MERKIN, Robert. Marine Insurance Legislation. Fourth Edition. Lloyd's Shipping Law Library. London, 2010

PEZOA, Renato. La máxima buena fe en el contrato de seguro marítimo. Navegando hacia la construcción de una micro-disciplina. Ediciones Jurídicas de Santiago. Santiago de Chile, 2020.

SOYER, Bariş. Warranties in Marine Insurance. Cavendish Publishing Limited. London, 2001.

Recebido em: $24 / 08 / 2020$

Aprovado em: 09/11/2020

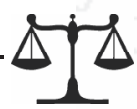

